\title{
Behaviors of beef cattle fed crude glycerol as a replacement for sorghum grain
}

Kaique Moreira Dias - Lorena Martins Oliveira - Matheus Silva Rodrigues •

Rowberta Teixeira dos Santos • Tiago do Prado Paim - Eduardo Rodrigues de Carvalho

KM Dias - LM Oliveira - MS Rodrigues - RT Santos - TP

Paim - ER Carvalho (Corresponding author)

Instituto Federal de Educação, Ciência e Tecnologia Goiano

(IF Goiano), Campus Iporá, GO, Brazil. email: eduardo.carvalho@ifgoiano.edu.br

Received: March 03, 2018 - Revised: May 11, 2018 • Accepted: May 12, 2018

\begin{abstract}
The study of the animal behavior is a useful tool to comprehend the performance of beef animals finished in feedlots. Twenty-eight non-castrated Nellore males with initial body weight of $441 \mathrm{~kg}$ and 21.5 months of age were randomly assigned to receive a diet containing either sorghum grain or crude glycerol as energy sources, and housed in individual (twelve animals) or collective pens (16 animals in four pens) at the School-Farm of IF Goiano (Iporá Campus). The experiment lasted 98 days (14 for adaptation and 84 for data collection). Feeding behaviors (eating, rumination, and resting) were determined every 14 days for one-hour intervals in four times post-feeding ( $0,1,5$, and 9 hours). Feed sorting was evaluated every 14 days in three times post-feeding (4, 10 , and 24 hours). Time spent eating was reduced $(\mathrm{P}<0.05)$ by crude glycerol in comparison with the sorghum grain diet (18.19 vs. 12.29 minutes/hour, sorghum vs. glycerol, respectively), while animals fed crude glycerol increased $(\mathrm{P}<0.05)$ the time spent resting compared with sorghum grainfed animals (26.23 vs. 32.85 minutes/hour, sorghum vs. glycerol, respectively). Substituting sorghum grain with crude glycerol increased $(\mathrm{P}<0.05)$ the preference for long $(44.77$ vs. $106.66 \%$, sorghum vs. glycerol, respectively), medium (64.95 vs. $105.78 \%$, sorghum vs. glycerol, respectively), and short (88.57 vs. $101.29 \%$, sorghum vs. glycerol, respectively) particles, whereas sorghum grain increased $(\mathrm{P}<0.05)$ the preference for fine particles of the diet (112.36 vs. $100.03 \%$, sorghum vs. glycerol, respectively). Crude glycerol can be recommended as a replacement for sorghum grain in rations fed to beef cattle.
\end{abstract}

Keywords: eating, particles, resting, rumination, sorting

\section{Introduction}

The study of animal behaviors has been used to evaluate different dietary strategies and the performance of beef cattle finished in feedlots, once the individual animal's activities can be assessed in its social and physical environment. As part of animal behavior, feeding behavior includes the activities of eating, drinking, ruminating and resting, and these are affected by climate, condition of teeth, age of the animal and characteristics of the diet (Albright 1993).

In general, ingredients of beef cattle diets have a wide range of nutritive value, fermentation rates, and ruminal digestibility. Consequently, the length of time that different feeds occupy space in the rumen varies, and therefore the time spent eating can be altered. In addition, intake, feeding rate, number of meals, meal duration and time spent ruminating are patterns that also change according to the chemical and physical characteristics of the diet (Dado and Allen 1993).

Accurate measurements of the effects of dietary manipulation on feeding behaviors are a valuable tool to interpret the performance of beef cattle finished in feedlots, therefore continuous and frequent observations are necessary to obtain reliable information from rapidly changing behavior activities (Dado and Allen 1993).

Feeding beef cattle with total mixed rations (TMR) are a common practice in feedlots, which consists in mixing all ingredients into a single feed mixture. The purpose of the TMR feeding system is to deliver to each beef animal a wellbalanced ration that is formulated to maintain health and maximize the daily weight gain. However, a major concern about feeding beef cattle with TMR is the intrinsic ability of the animals to selectively consume for or against the ingredients of the diet according to the particle size. This selective intake, which is commonly known by feed sorting, may result in a great variability of the nutritional value of the diet in comparison with what was initially formulated, and also may lead to the intake of a diet that does not meet the beef animals' daily nutrient needs (DeVries et al 2014).

Crude glycerol is a byproduct of the biodiesel industry that has been currently produced by a reaction that utilizes a base-catalyzed transesterification of vegetable oils or animal fat in the formation of methyl and ethyl fatty acid esters in the production of biodiesel, while crude glycerol is left behind as 
the byproduct (Ayoub and Abdullah 2012). As an example, for each $100 \mathrm{~g}$ of soybean oil input there is a yield of $12.25 \mathrm{~g}$ of crude glycerol, which is considered to be high in terms of a byproduct (Thompson and He 2006).

We hypothesized that crude glycerol in rations for beef cattle would maintain the activities of eating, ruminating, and resting (feeding behaviors) at an equivalent rate to the animals fed the sorghum grain diet. We also hypothesized that crude glycerol would increase the selective consumption (feed sorting) for the long $(>19 \mathrm{~mm})$ and medium $(<19,>8 \mathrm{~mm})$ particles of the diet due to its viscous property.

The objective of the present experiment was to determine the effects of substituting sorghum grain with crude glycerol in rations fed to beef cattle on the eating, ruminating, and resting activities (feeding behaviors), and also on feed sorting.

\section{Materials and Methods}

The present study was conducted at the Dairy and Beef Research and Education Center of the "Instituto Federal de Educação, Ciência e Tecnologia Goiano”, Iporá, Goiás State, Brazil, from June 29 through October 5, 2015. The experiment lasted 98 days, with 14 days of adaptation of the animals for the new facilities and experimental diets, and 84 days for data collection.

Twenty-eight non-castrated Nellore males with initial body weight (BW) of $441 \pm 40.2 \mathrm{~kg}$ and $21.5 \pm 0.5$ months of age were randomly assigned to receive either a diet containing sugar cane silage, ground corn cob, ground sorghum grain, soybean meal, protected urea, and a mineral/vitamin premix (control) or a diet in which ground sorghum grain was partially replaced with crude glycerol (Table 1).

After the first randomization by initial BW and age to each diet group (control or crude glycerol), animals were again randomly assigned according to the type of housing. Twelve animals were housed in individual pens and 16 animals were housed in four collective pens (four animals per pen).

The individual pens measured 2 meters wide by 5 meters long ( $10 \mathrm{~m}^{2} /$ animal) with provision of a $5 \mathrm{~m}^{2}$-shade by a zinc roof, whereas the collective pens measured 5 meters wide by 10 meters long $\left(12.5 \mathrm{~m}^{2} /\right.$ animal $)$ with no provision of shade. The volumetric capacity of feeders in the individual and collective pens was 0.35 and $1.05 \mathrm{~m}^{3}$, respectively. The length of the feed bunk in each collective pen was 3.8 meters, allowing $0.95 \mathrm{~m} /$ animal.

There were six drinkers alongside the twelve individual pens (one drinker for two animals) with a capacity of 240 liters. There were two drinkers that supplied water for the four collective pens (one drinker in the border between two pens) with a capacity of 380 liters. Drinkers in the individual pens were under shading and in the collective pens were exposed to the sun. All drinkers had automatic floats that allowed a continuous water flow.

Crude glycerol (80.5\% glycerol, $11.9 \%$ moisture, $5.2 \%$ $\mathrm{NaCl}$, and $50 \mathrm{mg}$ of methanol/kg of glycerol; donated by "ADM do Brasil LTDA") was included at $15 \%$ of the ration dry matter (DM) as a partial replacement for ground sorghum grain throughout the entire study (Table 1). Soybean meal was added in a higher quantity (three percentage units) in the crude glycerol diet to adjust the crude protein (CP) levels of diets (Table 1).

Animals were fed once daily between 05:00 to 07:00 am in amounts that ensured ad libitum intake (10 to $15 \%$ of orts). During the ensiling of sugar cane there was an addition of urea ( $1 \mathrm{~kg} / 100 \mathrm{~kg}$; green matter basis) to reduce the ethanol production during the fermentation process (Bravo-Martins et al 2006; Castro Neto et al 2008).

The experimental diets were formulated to contain similar levels of energy and CP, and balanced to meet the NRC (2000) guidelines for beef cattle in a feedlot system with an expected weight gain of $1.8 \mathrm{~kg} /$ day. All experimental protocols were approved by the IF Goiano Ethical Committee in the Use of Animals (decision \# 4/2015).

Eating, rumination, and resting activities (feeding behaviors) from individual animals were assessed on days 14 , $28,42,56,70$, and 84 days after the beginning of the study. In each day of sampling, feeding behaviors were observed over four one-hour periods. The first observation period began at the moment of feeding. The other periods were performed at one, five, and nine hours post-feeding. At each one-hour period, feeding behaviors were monitored for three-minute intervals through visual observation from individual animals (Martin and Bateson 2007).

An ethogram (Carvalho et al 2014) was developed to determine a time budget for eating, rumination, and resting activities (the latter two both standing and lying).

Eating was defined as obtaining or manipulating feed, chewing feed with the head in the feed bunk, or chewing feed with the head away from the feed bunk. The end of an eating bout was defined as the cessation, for more than three minutes, of the feeding behaviors described above.

Rumination (both standing and lying) was defined as manipulating a cud with repetitive jaw movements (clockwise or anticlockwise direction) that were not categorized as eating based on the description above. The end of a rumination bout was defined as the cessation, for more than three minutes, of the feeding behaviors described above.

Resting (both standing and lying) was defined as inactivity, drinking, or grooming and was terminated with the initiation of either an eating or a rumination bout. The characterization of the feeding behaviors described above were utilized to calculate the total time spent with eating, rumination and resting activities. 
Table 1 Ingredients and nutritional composition of the experimental diets ${ }^{\mathrm{a}}$.

\begin{tabular}{|c|c|c|}
\hline Ingredients, $\%$ of DM & Sorghum grain & Crude glycerol \\
\hline Sugar cane silage & 31.5 & 31.5 \\
\hline Ground corncob & 20.0 & 17.0 \\
\hline Ground sorghum grain & 33.5 & 18.5 \\
\hline Crude glycerol & - & 15.0 \\
\hline Soybean meal & 12.0 & 15.0 \\
\hline Protected urea (PROTE-N ${ }^{\circledR}$ ) & 0.5 & 0.5 \\
\hline Limestone $\left(\mathrm{CaCO}_{3}\right)$ & 0.8 & 0.8 \\
\hline Dicalcium phosphate $\left(\mathrm{CaHPO}_{4}\right)$ & 0.3 & 0.3 \\
\hline $\mathrm{NaCl}$ & 0.2 & 0.2 \\
\hline Mineral/vitamin premix ${ }^{b}$ & 1.2 & 1.2 \\
\hline \multicolumn{3}{|l|}{ Nutritional composition } \\
\hline $\mathrm{DM}^{\mathrm{c}}, \%$ & $63.2 \pm 3.4$ & $61.4 \pm 2.9$ \\
\hline $\mathrm{CP}^{\mathrm{d}}, \%$ of $\mathrm{DM}$ & $12.2 \pm 0.8$ & $12.1 \pm 1.0$ \\
\hline $\mathrm{NDF}^{\mathrm{e}}, \%$ of $\mathrm{DM}$ & $34.1 \pm 0.4$ & $30.0 \pm 0.9$ \\
\hline Ash, $\%$ of DM & $4.9 \pm 0.7$ & $6.1 \pm 0.9$ \\
\hline $\mathrm{GE}^{\mathrm{f}},(\mathrm{Mcal} / \mathrm{kg}$ of $\mathrm{DM})$ & $4.2 \pm 0.1$ & $4.1 \pm 0.1$ \\
\hline
\end{tabular}

Feed sorting was evaluated on days 13, 27, 41, 55, 69, and 83 days after the beginning of the experiment in three times relative to feed delivery $(4,10$, and 24 hours). In each of the times indicated, the amount of feed from individual and collective pens was briefly removed and weighed. A $1.4 \mathrm{~L}$ diet sample was collected at feed delivery (time zero), 4, 10, and 24 hours post-feeding (prior to removing and weighing the remaining feed), and stored frozen at $-4^{\circ} \mathrm{C}$. Soon after the end of the experiment, diet samples were thawed at room temperature and separated using the three-screen $(19,8$, and 4 $\mathrm{mm}$ ) and a bottom pan Penn State Particle Separator (PSPS, Nasco, Fort Atkinson, WI) to yield long ( $>19 \mathrm{~mm})$, medium $(<19,>8 \mathrm{~mm})$, short $(<8,>4 \mathrm{~mm})$ and fine $(<4 \mathrm{~mm})$ particles, following the method of Lammers et al (1996) and Kononoff et al (2003).

Post-separated materials were placed in aluminium trays, identified according to the animal's ear-tag, energy source (sorghum grain or crude glycerol), days of evaluation $(13,27,41,55,69$, and 83) and times post-feeding $(0,4,10$, and 24 hours), and then dried in a forced-air oven for 72 hours at $65^{\circ} \mathrm{C}$ for of for DM analysis (AOAC 2000).

The sorting index or simply feed sorting of the experimental diets was calculated by expressing the actual DM intake of each particle size as a percentage of the theoretical DM intake of the corresponding particle size (Leonardi and Armentano 2003), as described in the equations below:

$$
\begin{gathered}
\mathrm{TDMI}_{\mathrm{ps}}=\mathrm{DMI}_{\mathrm{t}} * \mathrm{PSD}_{\mathrm{t} 0} \\
\mathrm{ADMI}_{\mathrm{ps}}=\mathrm{DMI}_{\mathrm{t}} * \mathrm{PSD}_{\mathrm{t} 4, \mathrm{t} 10, \mathrm{t} 24} \\
\mathrm{SI}(\% \text { of DM })=\frac{\mathrm{ADMI}_{\mathrm{ps}} * 100}{\mathrm{TDMI}_{\mathrm{ps}}}
\end{gathered}
$$

$\mathrm{TDMI}_{\mathrm{ps}}=$ theoretical DM intake by particle size $(>19 \mathrm{~mm}$; $<19,>8 \mathrm{~mm}$; <8, >4 mm; <4 mm).

$\mathrm{ADMI}_{\mathrm{ps}}=$ actual DM intake by particle size $(>19 \mathrm{~mm} ;<19$, $>8 \mathrm{~mm} ;<8,>4 \mathrm{~mm} ;<4 \mathrm{~mm})$.

$\mathrm{DMI}_{\mathrm{t}}=\mathrm{DM}$ intake between $0-4,4-10$, and 10-24 hours postfeeding.

$\mathrm{PSDt}_{0}=$ particle size distribution at feed delivery (time zero).

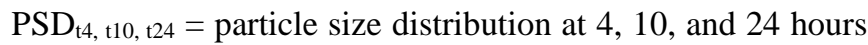
post-feeding.

SI $(\%$ of DM $)=$ sorting index or simply feed sorting.

Values $=100 \%$ indicate absence of sorting by particle size, values $<100 \%$ indicate selective refusal or sorting against by particle size, and values $>100 \%$ indicate selective consumption or sorting for by particle size (Leonardi and Armentano 2003).

The experimental design utilized was completely randomized in a factorial scheme $2 \times 2$ (two energy sources and two types of housing). The data were analyzed using the open system "R" (R Core Team 2014) in a mixed model of double repeated measurements in time, considering energy source (sorghum or crude glycerol) and type of housing (individual or collective pens) as fixed effects, and animal as random. The structure of covariance that best fitted to the model was chosen according to the lowest Bayesian Information Criterion.

The model accounted for the effects of energy source $(\mathrm{s})$, housing (h), days of experiment (d), times post-feeding (t), energy source $x$ days of experiment, energy source $x$ times post-feeding, energy source $\times$ days of experiment $\times$ times post-feeding, housing $\times$ days of experiment, housing $\times$ times post-feeding, housing $\times$ days of experiment $\times$ times post- 
feeding, energy source $x$ housing, energy source $x$ housing $x$ days of experiment, energy source $\times$ housing $\times$ times postfeeding, days of experiment $\times$ times post-feeding, and energy source $\times$ housing $\times$ days of experiment $\times$ times post-feeding, according to the following equation:

$\mathrm{y}_{\mathrm{ijklm}}=\mu+\mathrm{s}_{\mathrm{i}}+\mathrm{h}_{\mathrm{j}}+\mathrm{d}_{\mathrm{k}}+\mathrm{t}_{\mathrm{l}}+\mathrm{sd}_{\mathrm{ik}}+\mathrm{st}_{\mathrm{il}}+\mathrm{sdt}_{\mathrm{ikl}}+\mathrm{hd}_{\mathrm{jk}}+$ $\mathrm{ht}_{\mathrm{jl}}+\mathrm{hdt}_{\mathrm{jkl}}+\mathrm{sh}_{\mathrm{ij}}+\mathrm{shd}_{\mathrm{ijk}}+\mathrm{sht}_{\mathrm{ijl}}+\mathrm{dt}_{\mathrm{kl}}+$ shdt $_{\mathrm{ijkl}}+\mathrm{e}_{\mathrm{ijklm}}$; where $\mathrm{y}=$ independent variable, $\mu=$ mean, and $\mathrm{e}=$ experimental error. When a fixed effect was significant $(\mathrm{P} \leq 0.05)$, means were compared using the Tukey test. Values are reported as least square means and associated standard errors of means (SEM).

\section{Results and Discussion}

The time spent with both eating and resting was altered $(\mathrm{P}<0.05)$ by the energy source (Table 2$)$. Animals fed crude glycerol decreased $(\mathrm{P}<0.05)$ the mean time spent eating compared with the animals fed the sorghum grain diet (18.19 versus $12.29 \pm 1.09$ minutes/hour, sorghum grain versus crude glycerol, respectively; Table 2). Contrarily, animals fed crude glycerol rested for a longer $(\mathrm{P}<0.05)$ time in comparison with the animals fed the sorghum grain diet (26.23 versus $32.85 \pm$ 1.16 minutes/hour, control versus crude glycerol, respectively; Table 2). In addition, there was an energy source $x$ hours postfeeding effect $(\mathrm{P}<0.05)$, in which crude glycerol-fed animals reduced the time spent eating throughout the entire day compared with the sorghum grain-fed animals (Figure 1). The rumination activity was not changed $(\mathrm{P}>0.05)$ by crude glycerol feeding (Table 2). The findings in the present experiment refute the hypothesis that substituting sorghum grain with crude glycerol in the diet would maintain a similar time of the eating activity.

Although the animals fed crude glycerol had a reduction $(\mathrm{P}<0.05)$ on the mean time spent with the eating feeding behavior (Table 2$)$, as well as a decrease $(\mathrm{P}<0.05)$ on time spent eating during all hours post-feeding (Figure 1), the substitution of sorghum grain with crude glycerol did not affect the DM intake both in individual (11.34 versus 11.28 $\mathrm{kg} /$ day, sorghum grain versus crude glycerol, respectively) and collective pens ( 45.48 versus $45.15 \mathrm{~kg} /$ day, sorghum grain versus crude glycerol, respectively). Likewise, the growth performance was not altered by crude glycerol feeding $(510.3$ versus $514.2 \mathrm{~kg}$ of BW, sorghum grain versus crude glycerol, respectively).

One of the explanations why the replacement of sorghum grain by crude glycerol resulted in a reduction $(\mathrm{P}<0.05)$ on time spent eating but did have an influence on the DM intake and growth performance is based on the evidence that glycerol increased the molar proportion of propionate at the expense of acetate (Rémond et al 1993; Wang et al 2009; Carvalho et al. 2011; Ramos and Kerley 2012; Bartoň et al 2013) or can be directly absorbed by the rumen epithelium (Rémond et al 1993). In both scenarios, crude glycerol can act as a gluconeogenic precursor in the liver and consequently crude glycerol-fed animals in the present study may have been benefited from an enhanced energy status. This argument may explain the decreased $(\mathrm{P}<0.05)$ time on the eating activity but not a reduction on performance in animals fed crude glycerol.

Table 2 Effect of crude glycerol as a replacement for sorghum grain on eating, rumination, and resting activities (feeding behaviors).

\begin{tabular}{|c|c|c|c|c|c|c|c|c|c|c|c|c|}
\hline \multirow[b]{2}{*}{$\begin{array}{l}\text { Activities } \\
\text { (min/hour) }\end{array}$} & \multirow[b]{2}{*}{$\begin{array}{l}\text { Energy } \\
\text { source }\end{array}$} & \multicolumn{4}{|c|}{ Intervals post-feeding (h) } & \multirow[b]{2}{*}{ SEM $^{\mathrm{a}}$} & \multicolumn{6}{|c|}{ P-value } \\
\hline & & $0-1$ & $1-2$ & $5-6$ & $9-10$ & & Energy & Days $^{b}$ & Hours $^{\mathrm{c}}$ & $\begin{array}{l}\text { Energy } \\
\times \text { days }\end{array}$ & $\begin{array}{l}\text { Energy } \\
\times \text { hours }\end{array}$ & $\begin{array}{c}\text { Energy } \\
\times \text { days } \times \\
\text { hours }\end{array}$ \\
\hline \multirow{2}{*}{ Eating } & Sorghum & 33.8 & 12.6 & 10.6 & 15.7 & \multirow{2}{*}{1.3} & \multirow{2}{*}{$<0.05$} & \multirow{2}{*}{$<0.05$} & \multirow{2}{*}{$<0.05$} & \multirow{2}{*}{$<0.05$} & \multirow{2}{*}{$<0.05$} & \multirow{2}{*}{$<0.05$} \\
\hline & Glycerol & 22.4 & 6.8 & 6.8 & 13.1 & & & & & & & \\
\hline \multirow{2}{*}{ Rumination } & Sorghum & 5.3 & 22.7 & 20.7 & 13.6 & \multirow{2}{*}{1.4} & \multirow{2}{*}{0.60} & \multirow{2}{*}{$<0.05$} & \multirow{2}{*}{$<0.05$} & \multirow{2}{*}{0.55} & \multirow{2}{*}{0.69} & \multirow{2}{*}{0.73} \\
\hline & Glycerol & 6.0 & 20.4 & 20.0 & 13.1 & & & & & & & \\
\hline \multirow{2}{*}{ Resting } & Sorghum & 20.9 & 24.7 & 28.7 & 30.7 & \multirow{2}{*}{1.6} & \multirow{2}{*}{$<0.05$} & \multirow{2}{*}{$<0.05$} & \multirow{2}{*}{$<0.05$} & \multirow{2}{*}{0.09} & \multirow{2}{*}{$<0.05$} & \multirow{2}{*}{0.89} \\
\hline & Glycerol & 31.6 & 32.8 & 33.2 & 33.7 & & & & & & & \\
\hline
\end{tabular}

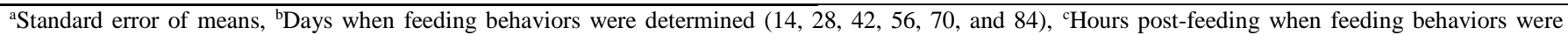
determined $(0,1,5$, and 9$)$

There was an effect $(\mathrm{P}<0.05)$ of energy source on the diet particle size distribution at feed delivery (Table 3 ). Crude glycerol increased the proportion of long (1.98 versus $2.42 \pm$ $0.09 \%$, sorghum grain versus crude glycerol, respectively), medium (10.36 versus $11.99 \pm 0.15 \%$, sorghum grain versus crude glycerol, respectively), and short (21.59 versus $24.00 \pm$ $0.27 \%$, sorghum grain versus crude glycerol, respectively) particles as a consequence of coating such particles due to its viscous nature (Ayoub and Abdullah 2012). Contrarily, the sorghum grain diet increased $(\mathrm{P}<0.05)$ the distribution of fine particles (66.07 versus $61.59 \pm 0.36 \%$, sorghum grain versus crude glycerol, respectively) of the diet (Table 3).

Feed sorting in the present work was assessed by collecting a $1.4 \mathrm{~L}$ sample, briefly removing the TMR from the feed bunk at each sampling time, weighing, and returning the TMR to the feed bunk. Although the particle size distribution of the TMR for all animals housed in individual and collective 
pens within a treatment (sorghum grain or crude glycerol) was the same at feed delivery, the profile of particles remaining at subsequent times may have differed. The data presented here evaluated the profile of particles present at each sampling time relative to the initial particle size distribution of the TMR, disregarding the individual feed sorting behavior patterns. The primary goal in this study was to evaluate the effect of substituting sorghum grain with crude glycerol in rations fed to beef cattle on the feed sorting behavior.

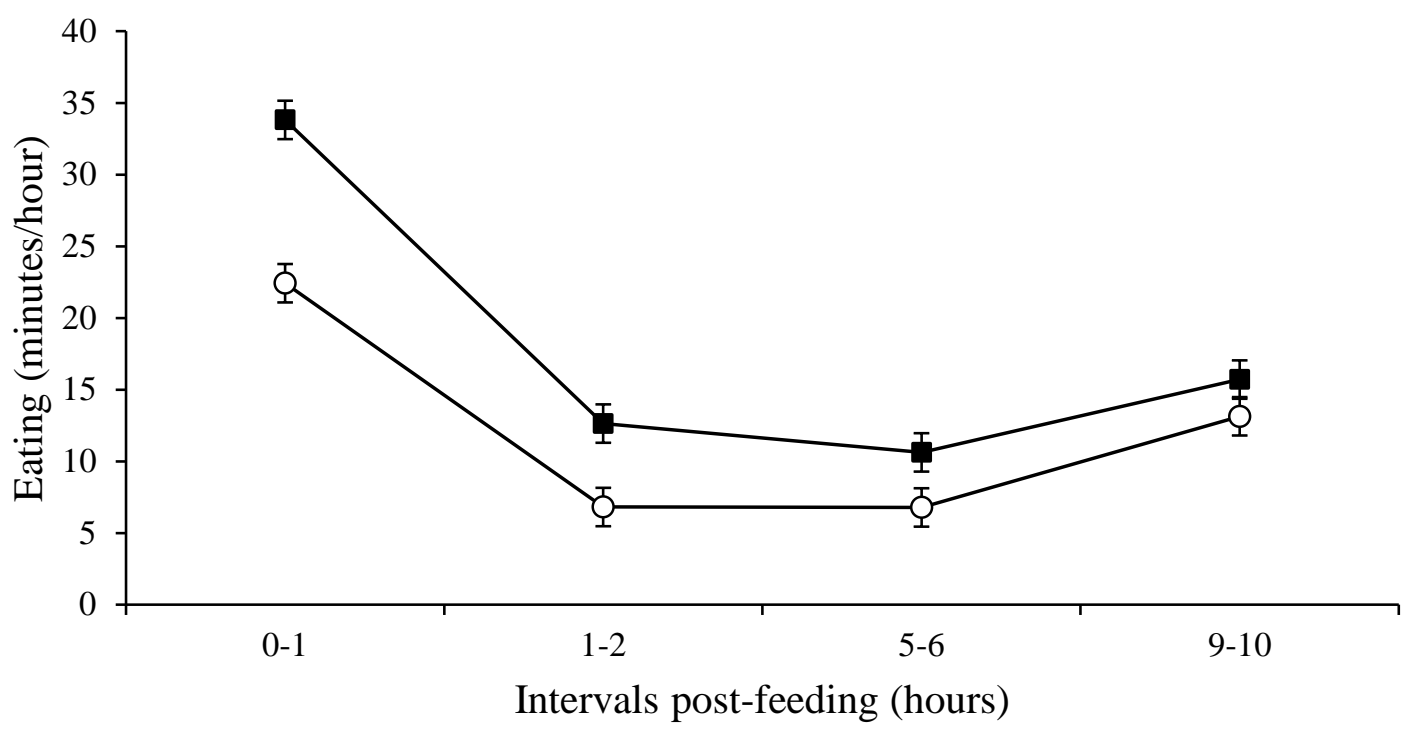

$\rightarrow$-Sorghum grain $\quad-0$-Crude glycerol

Figure 1 Effect of energy source (sorghum grain or crude glycerol) by hours post-feeding on time spent eating of 28 non-castrated Nellore males finished in a feedlot.

Similarly with the particle size distribution at feed delivery (time zero), a response $(\mathrm{P}<0.05)$ of energy source occurred on the feed sorting behavior of all classes of particle sizes (Table 4). Crude glycerol-fed animals increased the mean preference for long (44.77 versus $106.66 \pm 9.86 \%$, sorghum grain versus crude glycerol, respectively), medium (64.95 versus $105.78 \pm 3.24 \%$, sorghum grain versus crude glycerol, respectively), and short (88.57 versus $101.29 \pm$ $1.18 \%$, sorghum grain versus crude glycerol, respectively) particles, as opposed with the sorghum grain-fed animals that increased the mean preference for the fine particles of the diet (112.36 versus $100.03 \pm 0.96 \%$, sorghum grain versus crude glycerol, respectively). The data presented here support the hypothesis that substituting sorghum grain with crude glycerol increases the preferential consumption or preference for the long $(>19 \mathrm{~mm})$ and medium $(<19,>8 \mathrm{~mm})$ particles of the diet because of the potential of crude glycerol to coat such particles due to its viscous physical nature (Ayoub and Abdullah 2012). In addition, the data reported in Table 4 corroborates a previous finding that glycerol feeding to transition dairy cows also increased the preferential consumption for the long $(>19$ $\mathrm{mm})$ particles of the diet during the prepartum period and for the medium $(<19,>8 \mathrm{~mm})$ particles of the diet during the postpartum period (Carvalho et al 2012).

Table 3 Particle size distribution of the experimental diets at feed delivery

\begin{tabular}{lcccc}
\hline \% of DM retained on screen & Sorghum grain & Crude glycerol & SEM $^{\mathrm{a}}$ & $\mathrm{P}$ \\
\hline Long $(>19 \mathrm{~mm})$ & 1.98 & 2.42 & 0.09 & $<0.05$ \\
Medium $(<19,>8 \mathrm{~mm})$ & 10.36 & 11.99 & 0.15 & $<0.05$ \\
Short $(<8,>4 \mathrm{~mm})$ & 21.59 & 24.00 & 0.27 & $<0.05$ \\
Fine $(<4 \mathrm{~mm})$ & 66.07 & 61.59 & 0.36 & $<0.05$ \\
\hline${ }^{a}$ Standard error of means & & &
\end{tabular}

There was an energy source $\times$ hours post-feeding effect on the feed sorting behavior of all particle sizes (Figure 2; panels A, B, C, and D). Animals fed crude glycerol increased $(\mathrm{P}<0.05)$ the preference for the long $(>19 \mathrm{~mm})$ particles (Figure 2, panel A) within four and 24 hours after feed delivery (105.1 and $126.1 \pm 11.9 \%$ for 4 and 24 hours post- feeding, respectively), whereas animals fed the sorghum grain diet systematically displayed an increased $(\mathrm{P}<0.05)$ sorting against long $(>19 \mathrm{~mm})$ particles, a response that became evident as more time after feed delivery elapsed (65.8, 43.1, and $25.4 \pm 12.3 \%$ for 4,10 , and 24 hours post-feeding, respectively). 
A similar feed sorting behavior pattern occurred for the medium $(<19,>8 \mathrm{~mm})$ particles of the diet (Figure 2, panel B), in which crude glycerol-fed animals increased $(\mathrm{P}<0.05)$ the preference for the medium particles during the entire day (105.0, 100.3, and $112.1 \pm 4.2 \%$ for 4,10 , and 24 hours post- feeding, respectively), while the sorghum grain-fed animals increased $(\mathrm{P}<0.05)$ the selective refusal for medium particles across the day $(87.2,62.1$, and $45.5 \pm 4.6 \%$ for 4,10 , and 24 hours post-feeding, respectively).

Table 4 Effect of crude glycerol as a replacement for sorghum grain on feed sorting (\%) of long, medium, short, and fine particles.

\begin{tabular}{|c|c|c|c|c|c|c|c|c|c|}
\hline \multirow[b]{2}{*}{ Sorting index (\%) } & \multirow[b]{2}{*}{$\begin{array}{l}\text { Sorghum } \\
\text { grain }\end{array}$} & \multirow[b]{2}{*}{$\begin{array}{l}\text { Crude } \\
\text { glycerol }\end{array}$} & \multirow[b]{2}{*}{ SEM $^{\mathrm{a}}$} & \multicolumn{6}{|c|}{ P-value } \\
\hline & & & & Energy & Days $^{b}$ & Hours $^{c}$ & $\begin{array}{l}\text { Energy } \\
\times \text { days }\end{array}$ & $\begin{array}{l}\text { Energy } \\
\times \text { hours }\end{array}$ & $\begin{array}{c}\text { Energy } \\
\times \text { days } \\
\times \text { hours }\end{array}$ \\
\hline Long $(>19 \mathrm{~mm})$ & 44.77 & 106.66 & 9.86 & $<0.05$ & 0.33 & $<0.05$ & 0.59 & $<0.05$ & $<0.05$ \\
\hline $\begin{array}{l}\text { Medium }(<19,>8 \\
\text { mm) }\end{array}$ & 64.95 & 105.78 & 3.24 & $<0.05$ & $<0.05$ & $<0.05$ & $<0.05$ & $<0.05$ & $<0.05$ \\
\hline Short $(<8,>4 \mathrm{~mm})$ & 88.57 & 101.29 & 1.18 & $<0.05$ & $<0.05$ & $<0.05$ & 0.19 & $<0.05$ & 0.10 \\
\hline Fine $(<4 \mathrm{~mm})$ & 112.36 & 100.03 & 0.96 & $<0.05$ & $<0.05$ & $<0.05$ & 0.22 & $<0.05$ & 0.21 \\
\hline
\end{tabular}

${ }^{\mathrm{a}}$ Standard error of means, ${ }^{b}$ Days when feeding behaviors were determined (13, 27, 41, 55, 69, and 83), ${ }^{\mathrm{c} H o u r s ~ p o s t-f e e d i n g ~ w h e n ~ f e e d i n g ~}$
behaviors were determined (zero, 4, 10, and 24).
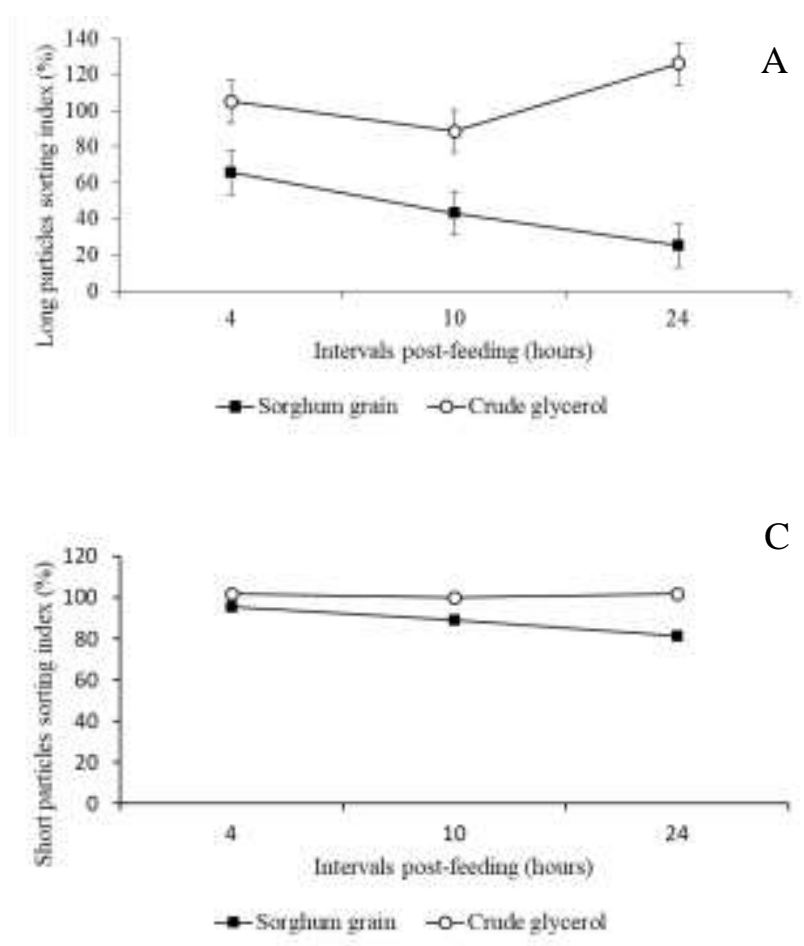
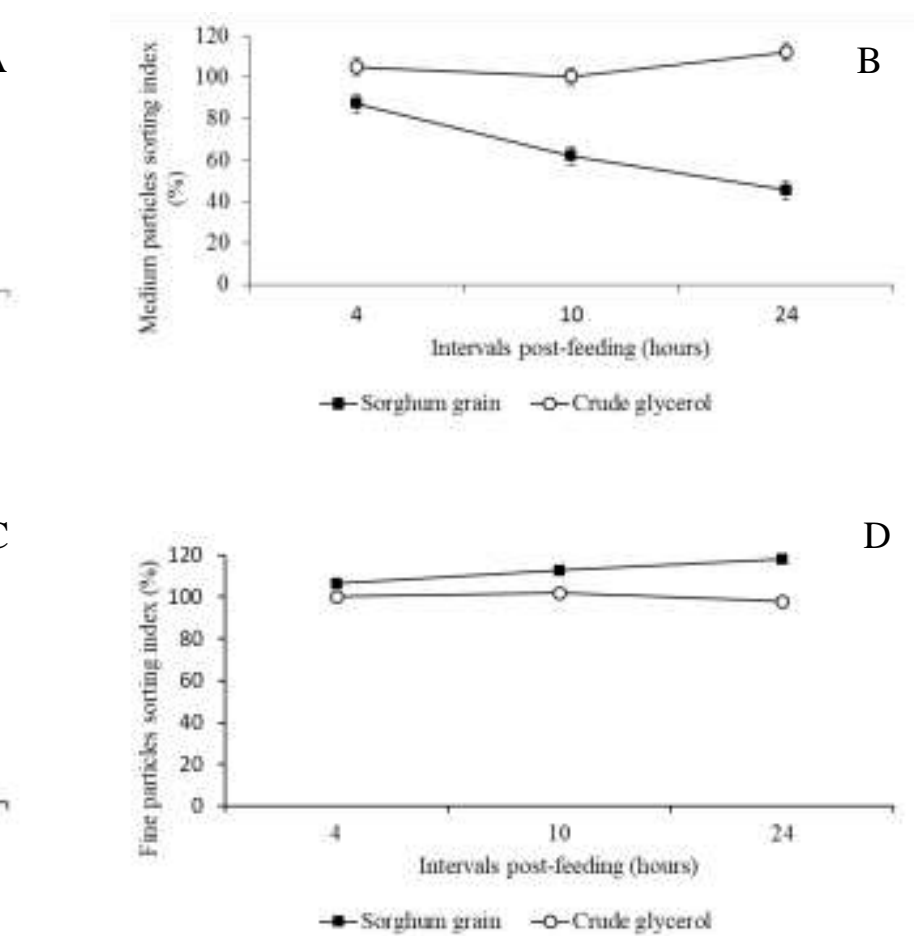

Figure 2 Effect of energy source (sorghum grain or crude glycerol) by hours post-feeding on the feed sorting of long (panel A), medium (panel B), short (panel C), and fine (panel D) particles of 28 non-castrated Nellore males finished in a feedlot.

The crude glycerol-fed animals displayed nearly a lack of sorting for the short particles (Figure 2, panel C) of the diet across the day $(101.9,99.9$, and $102.0 \pm 1.7 \%$ for 4,10 , and 24 hours post-feeding, respectively), whereas the sorghum grain-fed animals increased $(\mathrm{P}<0.05)$ the selective refusal for the short particles $(95.3,89.1$, and $81.2 \pm 1.9 \%$ for 4,10 , and 24 hours post-feeding, respectively). Contrarily, animals fed the sorghum grain diet increased $(\mathrm{P}<0.05)$ the preference for the fine particles of the diet (Figure 2, panel D) during the day $(106.5,112.7$, and $117.9 \pm 1.2 \%$ for 4,10 , and 24 hours post- feeding, respectively), whereas the animals fed the crude glycerol diet displayed indexes close to the absence of sorting $(100.2,102.1$, and $97.7 \pm 1.2 \%$ for 4,10 , and 24 hours postfeeding, respectively).

The preferential consumption or sorting for long ( $>19$ $\mathrm{mm})$ and medium $(<19,>8 \mathrm{~mm})$ particles displayed by crude glycerol feeding may be beneficial for beef animals finished in feedlots and fed diets that are normally rich in highlyfermentable carbohydrates in the rumen. The coating effect of crude glycerol on the long $(>19 \mathrm{~mm})$ and medium $(<19,>8$ 
$\mathrm{mm}$ ) particles may enhance the intake of long-stemmed forage (effective fiber), which in turn stimulates rumination, saliva production, and a stable rumen $\mathrm{pH}$ to prevent rumen acidosis (DeVries et al 2014).

\section{Conclusions}

Crude glycerol enhances the preferential consumption of long $(>19 \mathrm{~mm})$ and medium $(<19,>8 \mathrm{~mm})$ particles of the diet due to its coating effect on such classes of particles. This is a desirable behavior considering that beef animals fed crude glycerol will be stimulated to consume an energy source and effective fiber (long-stemmed forage) at the same time, and therefore may be less vulnerable to digestive disorders and rumen acidosis.

Crude glycerol can be safely recommended to replace sorghum grain in rations fed to beef cattle finished in feedlots with positive effects on animals' behaviors.

\section{Acknowledgements}

The authors wish to acknowledge the support of ADM do Brasil LTDA who generously donated five tons of crude glycerol for this project and the appreciation for Esmar Gonçalves da Cunha (MD and beef farmer) who lent 28 Nellore animals for this study. Scholarship support for Kaique Moreira Dias and Matheus Silva Rodrigues was from the Brazilian National Council for Scientific and Technological Development (CNPq), grant \# 487929/2013-6. Scholarship support for Rowberta Teixeira dos Santos was from "Fundação de Amparo à Pesquisa do Estado de Goiás" (FAPEG), grant \# 201510267000379.

\section{References}

Albright JL (1993) Feeding behavior of dairy cattle. Journal of Dairy Science 76:485-498.

Association of Official Analytical Chemists - AOAC (2000) Official methods of analysis. $17^{\text {th }}$ ed. AOAC International.

Ayoub M, Abdullah AZ (2012) Critical review on the current scenario and significance of crude glycerol resulting from biodiesel industry towards more sustainable renewable energy industry. Renewable and Sustainable Energy Reviews. doi: 10.1016/j.rser.2012.01.054

Bartoň L, Bureš D, Homolka P, Jančík F, Marounek M, Řehák D (2013) Effects of long-term feeding of crude glycerine on performance, carcass traits, meat quality, and blood and rumen metabolites of finishing bulls. Livestock Science. doi: 10.1016/j.livsci.2013.04.010

Bravo-Martins CEC, Carneiro H, Castro-Gómez RJH, Figueiredo HCP, Schwan RF (2006) Chemical and microbiological evaluation of ensiled sugar cane with different additives. Brazilian Journal of Microbiology 37:499-504.

Carvalho ER, Schmelz-Roberts NS, White HM, Doane PH, Donkin SS (2011) Replacing corn with glycerol in diets for transition dairy cows. Journal of Dairy Science. doi: 10.3168/jds/2010-3581
Carvalho ER, Schmelz-Roberts NS, White HM, Wilcox CS, Eicher SD, Donkin SS (2012) Feeding behaviors of transition dairy cows fed glycerol as a replacement for corn. Journal of Dairy Science. doi: $10.3168 /$ jds.2010-3584

Carvalho ER, Schmelz-Roberts NS, White HM, Wilcox S, Eicher S, Donkin SS (2014) Eating, resting and rumination activities of transition dairy cows fed with glycerol. Global Science and Technology 7:130-141.

Castro Neto AG, Molina LR, Gonçalves LC, Jayme CG (2008) Parâmetros de fermentação de silagens de cana-de-açúcar submetidas a diferentes tratamentos. Arquivo Brasileiro de Medicina Veterinária e Zootecnia 60:1150-1156.

Dado RG, Allen MS (1993) Continuous computer acquisition of feed and water intakes, chewing, reticular motility, and ruminal $\mathrm{pH}$ of cattle. Journal of Dairy Science. doi: http://dx.doi.org/10.3168/jds.S0022-0302(93)77492-5

DeVries TJ, Schwaiger T, Beauchemin KA, Penner GB (2014) Impact of severity of ruminal acidosis on feed-sorting behaviour of feed cattle. Animal Production Science. doi: http://dx.doi.org/10.1071/AN14227

Kononoff PJ, Heinrichs AJ, Buckmaster DR (2003) Modification of the Penn State forage and total mixed ration particle separator and the effects of moisture content on its measurements. Journal of Dairy Science. doi:10.3168/jds.S0022-0302(03)73773-4

Lammers BP, Buckmaster DR, Heinrichs AJ (1996) A simple method for the analysis of particle sizes of forage and total mixed rations. Journal of Dairy Science. doi:10.3168/jds.S00220302(96)76442-1

Leonardi C, Armentano LE (2003) Effect of quantity, quality, and length of alfalfa hay on selective consumption by dairy cows. Journal of Dairy Science. doi: 10.3168/jds.S0022-0302(03)73634-0

Martin P, Bateson P (2007) Measuring behavior: an introductory guide. Cambridge University Press, Cambridge, UK.

National Research Council - NRC (2000) Nutrient requirements of beef cattle. $7^{\text {th }}$ revised edition. National Academy Press, Washington, DC.

R Core Team (2014) A language and environment for statistical computing. Viena: R Foundation for Statistical Computing. Available at: http://www.R-project.org/. Accessed in June 29, 2016.

Ramos MH, Kerley MS (2012) Effect of dietary crude glycerol level on ruminal fermentation in continuous culture and growth performance of beef calves. Journal of Animal Science. doi: 10.2527/jas.2011-4099

Rémond B, Souday E, Jouany JP (1993) In vitro and in vivo fermentation of glycerol by rumen microbes. Animal Feed Science and Technology 41:121-132.

Thompson JC, He BB (2006) Characterization of crude glycerol from biodiesel production from multiple feedstocks. Applied Engineering in Agriculture 22:261-265.

Wang C, Liu Q, Huo WJ, Yang WZ, Dong KH, Huang YX, Guo G (2009) Effects of glycerol on rumen fermentation, urinary excretion of purine derivatives and feed digestibility in steers. Livestock Science. doi: 10.1016/j.livsci.2008.05.010 